\section{The brighter way to cure}

Can you be sure that your curing light is reaching beyond the surface to the depths of the deepest cavities?

With the Elipar DeepCure S LED curing light from 3M Oral Care you can rest assured that deep curing will not provide any problems.

Able to cure a vast majority of dental materials, this LED light has a consistent light output that will not weaken even during prolonged curing sessions, making sure that professionals can cure the deepest restorations without worry.
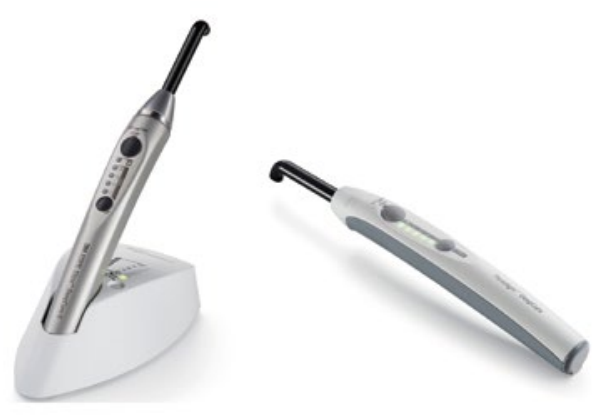

Furthermore, despite the intensity of the light being high, it is pulp-friendly and covers a wide $10 \mathrm{~mm}$ range so that curing is both straightforward and safe.

Shine a light on the deepest restorations by contacting the team at $3 \mathrm{M}$ Oral Care.

For more information, call 0800626 578 or visit www. 3 m.co.uk/Dental.

$3 \mathrm{M}$ and Elipar are trademarks of the 3M Company.

\section{Large manufacturer of professional dental products and technologies wins Top Employer award}

The Top Employers Institute has recognised Dentsply Sirona - the world's largest manufacturer of professional dental products and technologies - as top employer in Germany and Switzerland.

The Institute recognised Dentsply Sirona for its excellence in personnel management and strategy and honoured the company as Top Employer Germany Engineers and Top Employer Switzerland.

This is the seventh year in a row that Dentsply Sirona has received this distinction.

This award honoured the world's largest manufacturer of dental products for its exemplary personnel management and strategy and its exceptional personnel programmes.

Since 1991, the Top Employers Institute, which is based in the Netherlands, has been examining participating companies from all over the world for this award according to standard criteria.

In order to achieve certification, companies must meet the Institute's requirements of an above-average standard.

The awards were presented during the traditional Certification Dinner at the Areal Böhler, Düsseldorf, on February 122019.

In addition to the thorough assessment by the Top Employers Institute, all of the results are also subjected to an external examination and audit.

The external audit noted Dentsply Sirona's extraordinary performance with regard to employee orientation - which is why the company was certified as Top Employer.

Maureen MacInnis, Senior Vice President, Chief Human Resources Officer and Communications for the company, said: 'We

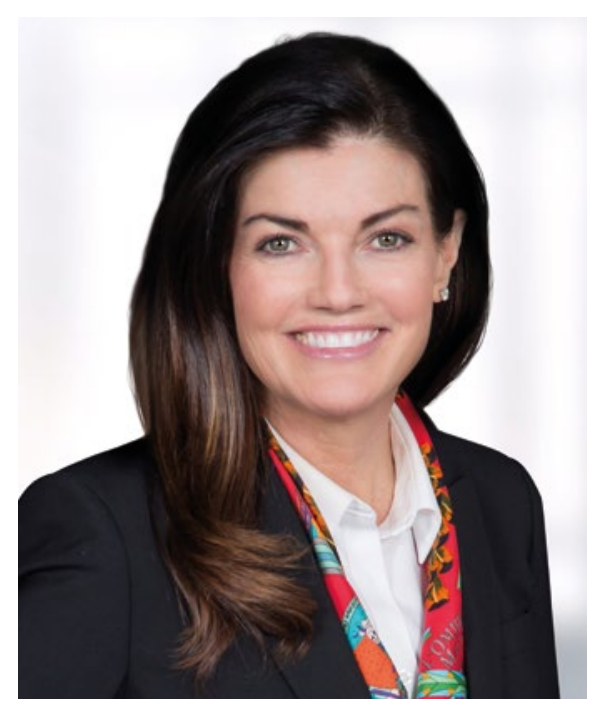

are very pleased to have received the Top Employer Award once again this year. This reaffirms our personnel strategy, because at Dentsply Sirona, our employees are our greatest asset.'

Through its Dentsply Sirona University, the company offers a variety of courses in which employees can participate to strengthen their skills and develop their careers.

Dentsply Sirona said it also fostered diversity and inclusion throughout the organisation.

For example, one programme, known as the Women Inspired Network (WIN), provides a platform for women leaders at Dentsply Sirona to support the acceleration of their career development by building key leadership competencies and developing stronger networks.

Now in its fourth year, the current cohort includes 27 participants, who join the more than 75 who are already part of the Network.

\title{
Maximum oiling, minimal consumption
}

Dental professionals can improve the efficacy of handpiece maintenance procedures with the innovative Assistina TWIN from leading manufacturer, W\&H.

As the first reprocessing device to feature a dual chamber design, the Assistina TWIN enables practitioners to alternate instruments for non-stop loading. It is designed to reprocess each handpiece to a consistently high standard within just ten seconds, facilitating more efficient decontamination processes.

The Assistina TWIN uses oil nebulisation technology to disperse a fine oil mist at high pressure. This ensures safe and effective removal of any harmful contaminants, whilst also ensuring consistent lubrication of handpieces.

More information is available by visiting www.wh.com/en_uk, calling 01727874990 , or emailingoffice.uk@wh.com. 